\title{
Teorias marxistas da inflação: uma revisão crítica
}

Marxist theories of inflation: a critical review

\author{
Giliad de Souza Silva \\ Universidade Federal do Sul e Sudeste do Pará \\ Eduardo Augusto de Lima Maldonado Filho \\ Universidade Federal do Rio Grande do Sul
}

\begin{abstract}
The inflationary phenomenon becomes relevant in the economic literature after the 1960 s, from the moment when inflation turn into a problem of greater magnitude and with a deep rooting in the advanced capitalist countries. Marxism has built his explanations of the inflation based principally on the following approaches: i) conflicts over the distribution of income are, in short, the most significant cause of inflation; ii) inflation is linked to the growing power of monopolies, being reinforced by the interventionist policies of the State; and iii) the phenomenon is explained by the discrepancy between endogenous generated increases in supply and demand for credit money. The aim of this paper is to revisit these Marxist approaches, as found in Saad-Filho (2000), but emphasizing the methodological critique. More specifically, our goal is to perform a methodological critique showing the continued validity of Marx's method to understand the inflation phenomenon of post World War II.
\end{abstract}

\section{Keywords}

theory of distributive conflict; theory of monopoly capital; theory of extra money; method of Marx.

JEL Codes B24; E31.

\section{Resumo}

O fenômeno inflacionário passa a assumir lugar de destaque na literatura econômica após a década de 1960, exatamente no momento em que tal fenômeno se torna um problema de maior amplitude e com um profundo enraizamento nos países capitalistas avançados. O marxismo construiu suas explicações sobre a inflação baseado sobretudo nas seguintes abordagens: i) que os conflitos sobre a distribuição da renda são, em suma, a causa mais significativa da inflação; ii) que a inflação está vinculada ao crescente poder dos monopólios, sendo reforçado pelas políticas intervencionistas do Estado; e iii) que o fenômeno é explicado pela discrepância gerada endogenamente entre os aumentos da oferta e da demanda do dinheiro de crédito. O objetivo deste texto é revisitar estas abordagens marxistas, assim como fez Saad-Filho (2000), porém avançando na crítica metodológica. Mais especificamente, nosso objetivo é o de, revisitando essas abordagens teóricas, realizar uma crítica metodológica mostrando a continuidade da validade do método de Marx para compreender o fenômeno da inflação do pós-segunda guerra mundial.

\section{Palavras-chave}

teoria do conflito distributivo; teoria do capital monopolista; teoria da moeda extra; método de Marx.

Códigos JEL B24; E31. 


\section{Introdução}

A literatura econômica atual se debruça sobre o fenômeno inflacionário com certa regularidade. Muitas vezes objetivando medir a eficiência das políticas anti-inflacionárias convencionais ou mesmo propondo saídas alternativas à orientaçãodo mainstream. Do ponto de vista teórico, as abordagens convencionais são reconhecidamente deficientes na compreensão desse fenômeno, o que torna tanto o debate teórico quanto aquele relacionado com a adoção de políticas macroeconômicas de combate ao processo inflacionário bastante controversos. No campo marxista, o quadro não é diferente, conforme veremos abaixo.

É importante destacar, ainda, que esse não seja o objeto específico de estudo desse artigo, que o processo inflacionário atual possui características que o diferenciam dos fenômenos inflacionários observados no período anterior à segunda guerra mundial. ${ }^{1}$ Cabe também registrar que a palavra "inflação", segundo Bryan (2002), surge no meio teórico entre meados da década de 1830 e a Guerra Civil Americana (1861-65), associada ao descompasso entre o montante de papel-moeda em circulação e a quantidade de dinheiro metálico que o lastreava, descompasso esse estimulado pelo financiamento da guerra civil. ${ }^{2} \mathrm{Na}$ virada do século XIX para o $\mathrm{XX}$, os economistas passaram a se referir a qualquer meio circulante como dinheiro, pelo simples fato da mercadoria-dinheiro e seus representantes diretos estarem cada vez mais apartados da circulação, que estava sendo progressivamente hegemonizada pelo dinheiro de crédito. Se, para a maior parte das teorias econômicas, esta mudança teve pouco significado, para o marxismo, tal generalização pode provocar confusões na compreensão dos fenômenos monetários, em especial no abandono da teoria monetária de Marx como instrumento teórico para a compreensão do fenômeno

1 "Inflation was the main factor that distinguished the present from the past. From 1800 to 1940, the cost of living [in the USA] had risen an average of only $0.2 \%$ a year and had actually declined on 69 occasions. In 1940 the cost-of-living index was only 28\% higher than it had been 140 years earlier. ... The Second World War and its aftermath changed all that. From 1941 to 1959, inflation averaged $4.0 \%$ a year, with the cost-of-living index rising every year but one" (Bernstein, 1996, p. 184).

2 "The era between the mid-1830s and the Civil War-a period economists refer to as the 'free banking era' - saw a proliferation of banks. Along with these institutions came "bank notes," a private paper currency redeemable for a specific amount of metal. That is, if the issuing bank had it. At times, banks did not have enough gold or silver to satisfy all of their claims. Bank notes, like the public notes that preceded them, also tended to depreciate. It is during this period that the word inflation begins to emerge in the literature, not in reference to something that happens to prices, but as something that happens to a paper currency." (Bryan, 2002, p.595). 
inflacionário. Outro desdobramento deste fato é que a inflação passou a ser entendida como qualquer aumento no nível dos preços, sendo comum ouvir falar de inflação de salários, inflação de energia, etc. Se os clássicos viam inflação como um fenômeno monetário oriundo da mudança no padrão dos preços, contemporaneamente se torna sinônimo de qualquer aumento de preço (Bryan, 2002).

É válido destacar que este fenômeno sempre foi tratado como secundário pelas razões já apontadas acima, a saber: não havia uma tendência secular de crescimento da inflação. O comportamento dos preços alternava-se sempre entre momentos inflacionários e deflacionários, dependendo da fase no ciclo econômico. $\bigcirc$ foco na análise da inflação enquanto tendência de longo prazo só assumiu centralidade ao longo dos anos 1960, em outras palavras, exatamente no momento em que a inflação se torna um problema de maior amplitude e com um profundo enraizamento nos países capitalistas avançados. Do ponto de vista da classe capitalista, a inflação passa a ser vista como um dos principais problemas econômicos a ser combatido pelo Estado. ${ }^{3}$ Consequentemente, os economistas mainstream colocaram o entendimento do processo inflacionário no centro de suas preocupações teóricas e de políticas macroeconômicas.

Evidentemente que a compreensão do processo inflacionário, pelas razões apontadas acima, também assume lugar de destaque nas análises teóricas dos economistas marxistas. Era necessário entendê-la, compreender seus meandros, suas relações internas, suas vinculações (ou não) com a lógica econômica mais ampla. $\bigcirc$ marxismo construiu suas explicações baseadas sobretudo nos seguintes argumentos: i) que os conflitos sobre a distribuição da renda são, em suma, a causa mais significativa da inflação. Esta linha argumentativa ganhou destaque entre os Marxistas por causa da

3 "Outro aspecto a considerar é que como resultado das baixas taxas de juros e da aceleração do processo inflacionário, os anos 1970 foram desastrosos para os investidores capitalistas (i.e., rentistas). Por exemplo, o valor real de um investimento no mercado de capitais em 1969 estaria reduzido praticamente à metade dez anos depois. A responsabilidade pela inflação - e, portanto, pelo "roubo" de seus capitais - era atribuída ao governo, principalmente por decorrência dos gastos sociais crescentes, que geravam os déficits públicos e que, por sua vez, se constituíam no principal determinante da inflação. Assim, do ponto de vista dos capitalistas, o principal problema econômico era a inflação - e não o desemprego - e, em termos estruturais, a solução era retornar ao liberalismo econômico. No que diz respeito à política macroeconômica, a visão monetarista tornou-se hegemônica. A política fiscal deveria ser conduzida de forma a equilibrar as contas do governo e a política monetária deveria ser conduzida pelo FED através do sistema de metas monetárias com o objetivo de controlar o processo inflacionário" (Maldonado Filho, 2005, p. 390). 
relação aparente entre este conceito e o da luta de classes; ii) que a inflação está vinculada ao crescente poder dos monopólios, sendo reforçado pelas políticas intervencionistas do Estado. Esta explicação é constitutiva da abordagem sobre poder de monopólio e subconsumo - baseada em Baran e Sweezy (1974); e iii) que o fenômeno é explicado pela discrepância gerada endogenamente entre os aumentos da oferta e da demanda do dinheiro de crédito. Este argumento destaca a importância monetária ao processo inflacionário, ao contrário dos outros dois.

O objetivo deste texto é revisitar as principais abordagens marxista em relação ao processo inflacionário, assim como fez Saad-Filho (2000), porém avançando na crítica metodológica. Mais especificamente, nosso objetivo neste artigo é o de, revisitando essas abordagens teóricas, realizar uma crítica metodológica mostrando a continuidade da validade do método de Marx para compreender o fenômeno da inflação do pós-Segunda Guerra Mundial. Cabe destacar que não se intenta aqui propor uma formulação teórica acabada sobre tal fenômeno, porém apresentar indícios de um afastamento destas abordagens marxistas, com o corpo teórico-metodológico construído por Marx.

O presente artigo está organizado em 4 seções, além desta introdução e das conclusões. As três primeiras discutem as principais linhas marxistas interpretativas da inflação, respectivamente: i) do conflito distributivo, ii) do capital monopolista; e iii) da moeda extra. Nelas serão apresentadas sinteticamente os pontos mais relevantes, destacando os textos seminais, assim como as questões polêmicas e as que contrariam a teoria do Marx. A quarta seção se constitui de uma crítica metodológica a tais abordagens, indicando que elas recorrentemente caem no erro das teorias convencionais, a saber, analisar os fatos baseado no uso de abstrações equivocadas, focando especialmente na aparência dos fenômenos.

\section{Teoria do conflito distributivo}

A teoria de inflação por conflito distributivo, que se inspira na teoria do cost-push (inflação de custos), afasta-se do pressuposto do equilíbrio, e assume que a oferta de moeda é plenamente endógena, que as políticas monetária e fiscal são passivas, e que os agentes-chave (no caso, os capitalistas monopolistas e os trabalhadores sindicalizados) têm poder de mercado e podem definir o preço de seus produtos ou serviços em grande parte de 
forma independente da demanda. Inflação surge porque a soma de reivindicações (claims) sobre o produto nacional (que depende dos níveis de renda alvo, da participação no produto nacional, ou das taxas de crescimento da renda) é maior do que a renda real disponível. Há inflação porque o banco central valida, diretamente ou por meio de seu apoio ao sistema financeiro, demandas incompatíveis para a participação na renda nacional pela acomodação monetária, numa tentativa de proteger as instituições financeiras e assegurar a continuidade da produção. Ela varia positivamente as alterações do tamanho das reivindicações sobrepostas (no caso, quando reivindicações das classes-chave, no agregado, são superiores à renda disponível), a frequência das mudanças de preços e salários e o nível de utilização da capacidade instalada, variando negativamente em relação à taxa de crescimento da produtividade (Saad-Filho, 2000; Rowthorn, 1982).

A inflação funciona como um mecanismo de distribuição de renda quando um dos agentes-chave é incapaz de prevê-la. ${ }^{4}$ Caso o fosse, tal agente tomaria medidas para se proteger de seus efeitos. A renda disponível (aquela que é objeto de reivindicação dos trabalhadores privados e dos capitalistas domésticos) é o equivalente à renda total deduzida a renda de determinação exógena, no caso, do Estado (impostos) e dos fornecedores estrangeiros (custo de importação). Como não há mecanismo automático que garanta a distribuição entre salários (renda dos trabalhadores) e lucros (renda dos capitalistas), as reivindicações dos rivais referentes ao objeto podem superar o que ficou disponível após o pagamento da renda exógena. Haveria, assim, um conflito no tocante à política de preços capitalista e a decisão frente ao que foi negociado pelo acordo salarial. Esse imbróglio seria desvelado pela discrepância entre o lucro alvo aplicado pelos capitalistas por meio de sua política de preços e o lucro negociado (que leva em conta a inflação esperada). Isto é o que Rowthorn (1982, p. 139) chama de "hiato de aspiração", sendo o determinante, em última instância, do fenômeno inflacionário. Um hiato de aspiração positivo, derivado de um lucro alvo superior àquele negociado no acordo salarial, significa uma taxa não prevista de inflação. Nessa situação, poderia até haver aumento nominal dos salários, porém os salários reais cairiam ou ficariam constantes.

4 "[Expectativa] refere-se a um estado de espírito, [previsão], a um comportamento real. Esperar alguma coisa significa simplesmente acreditar, com maior ou menor confiança, que ela ocorrerá, enquanto prever significa tanto esperar como agir com base nessas expectativas." (Rowthorn, 1982, p. 137). 
A renda disponível teria a sua taxa de crescimento em termos de ganhos de produtividade. Sempre que há aumento da taxa de lucro ou de salários maior do que os ganhos de produtividade, o resultado é inflação. Desse pressuposto da teoria do conflito original, pode-se incluir outras determinantes, como é exposto por Saad-Filho.

The model can be refined endlessly by incorporating target income levels, expectations, reaction functions, and limits on the wage claims because of unemployment, or on the mark up because of competition. It naturally follows that, when inflation is anticipated, the process of income transfer becomes less efficient and inflation rates must increase in order to achieve the same results. (Saad-Filho, 2000, p. 338).

A inflação não prevista poderia ser evitada caso existisse uma política eficiente de coordenação dos salários e preços. Caso os trabalhadores estejam bem organizados e com muita força no mercado de trabalho, poderia haver um achatamento dos lucros, constrangendo de certa forma os investimentos e, por fim, a atividade econômica. Se o mercado de produto for monopolista, as empresas terão força para empreender uma política de preços agressiva, visando obter maior parcela da renda. A consequência disso é inflação e transferência de renda dos trabalhadores aos capitalistas via perda dos salários reais. Uma política bem-sucedida seria aquela que coordenasse as reivindicações salariais e de lucros, sem desestimular a atividade econômica e nem desencadear um processo de inflação não prevista. Em última instância, o controle inflacionário seria uma questão de boa política.

Há uma ausência deliberada de teoria monetária dentro dessa abordagem. Como a inflação é causada pelo conflito nas reivindicações sobre a renda, qualquer impacto monetário sobre a mudança nos preços só se daria mediante efeitos sobre a distribuição da renda, logo, quando afeta o conflito. "Não existe espaço para uma teoria monetária que postule um elo causal direto entre moeda e preços, pois esse elo proporcionaria uma segunda e independente explanação da inflação" (Rowthorn, 1982, p. 155). E o principal modo da moeda afetar a distribuição de renda é com seus impactos sobre a demanda. Tendo em vista que o nível de demanda é um fator causal sobre o conflito, já que determina a posição dos agentes-chave no mercado de mão de obra e de produtos, uma alteração na moeda que conduza a mudanças no nível de demanda é capaz de afetar, também, o grau do conflito. Este seria o canal sobre o qual os fatores monetários impactariam na taxa de inflação. Assim, a moeda não seria entendida como neutra, haja vista seu papel ativo e a capacidade dos fatores monetários de exercer uma influência independente sobre a atividade econômica. No entanto, isto não 
significa dizer que "a moeda seja o único fator capaz de exercer influência independente sobre a atividade econômica. $O$ controle monetário é apenas uma das armas da 'administração da demanda' e em geral vem acompanhado de medidas fiscais" (Rowthorn, 1982, p. 156). Em outras palavras, os fatores monetários têm importância secundária na causalidade da inflação, e apenas quando eles alteram de algum modo o grau de conflito.

Rowthorn (1982) afirma que esta abordagem tem muitas similitudes com a teoria monetarista "neoclássica". Poderíamos apontar alguns pressupostos que as aproximam, como: a percepção do Estado como um agente exógeno; ${ }^{5}$ a suposição da Paridade do Poder de Compra; ${ }^{6}$ a suposição de que o comportamento combativo do movimento dos trabalhadores sempre tem impacto inflacionário; o uso da curva de Phillips-Friedman-Phelps enquanto instrumento analítico; ${ }^{7}$ o uso de expectativas adaptativas, à la Friedman; a compreensão teórica da existência de um estado de equilíbrio (Steady State), entre outras. O que é apontado pelo autor como ponto em comum é a compreensão de que a oferta de moeda, mediante seus impactos no comportamento dos gastos, influencia a demanda e esta, por sua vez, afeta os preços. "Ademais, o mecanismo de expectativas adaptativas garante que a amplitude de administração da demanda seja limitada pela possibilidade de inflação explosiva." (Rowthorn, 1982, 160).

Rowthorn (1982) define monetarismo "neoclássico" como aquele que supõe o desempenho atomístico do capitalismo, com sindicatos e firmas inexpressivos em relação à economia como um todo e agem de maneira independente dos seus pares, sem qualquer cooperação ou emulação de comportamento. O Estado teria um papel irrelevante na determinação de preços e salários, e função da política e da ideologia seriam de pouca relevância. A crítica de Rowthorn ao monetarismo "neoclássico", em suma, versa quase exclusivamente ao aspecto da estrutura de mercado no qual aquela abordagem pressupõe. Para além da incompatibilidade do conceito de estruturais de mercado com a teoria da concorrência do Marx, que será desenvolvido mais adiante, não há qualquer crítica ao método, aos pressupostos e ao escopo de Rowthorn (1982) ao monetarismo "neoclássico".

5 Marx tinha uma posição inequívoca da completa vinculação do Estado com a sociedade e seus modos de reprodução da vida humana. Sobre a posição de Marx, ver Draper (1977, cap. 11).

6 Uma crítica marxista ao pressuposto da Paridade do Poder de Compra, ver Shaikh (2000b).

7 Para uma crítica marxista a esta curva de Phillips, ver Shaikh (2000a). 
Saad-Filho (2000) aponta uma série de críticas a essa abordagem, que podem ser sintetizadas nos seguintes pontos: i) o que ver parcerias potenciais entre classes sociais antagônicas, cuja possibilita de alcançar estabilidade econômica se dá mediante negociação da política de distribuição de renda; ii) o de supor que a barganha sobre a participação na renda é um fato fundamental na determinação dos preços, quando tal distribuição é feita ex post, em vez de ser o objeto de disputa; iii) a de compreender que a inflação existe em função de um deslocamento que muda a economia para longe de um equilíbrio Pareto ótimo; iv) o de possuir uma abordagem tautológica que é cientificamente infundada, porque sua análise não se lastreia numa estrutura mais ampla que dê suporte aos seus conceitos elementares e que contextualize suas conclusões; v) o de derivar o papel do Estado e de suas políticas a partir de um conjunto de fatos estilizados. O motivo e o alcance das políticas econômicas não são explicados, além de depender fortemente da subjetividade do analista; e, vi) de que esta abordagem tem que se relacionar com uma abordagem teórica que é não marxista. Ademais, as similitudes entre a abordagem do conflito distributivo e o monetarismo "neoclássico", apresentadas por Rowthorn (1982), já são, em si, razões suficientes para mostrar o gritante descolamento desta abordagem com a teoria econômica de Marx. Como a variação dos preços é determinada em última instância pelas reivindicações em torno da renda disponível, é presumível que não haja um lastro da teoria do valor-trabalho, muito menos o pressuposto do Marx de que toda mercadoria entra na circulação com um preço.

\section{Teoria do capital monopolista}

A abordagem originada por Baran e Sweezy (1974), cuja edição original é de 1966, e com diversas contribuições trazidas sistematicamente na revista Marxista Monthly Review, teve forte impacto dentro do marxismo, sobretudo nas análises econômicas. É válido destacar que, como elementos significativos de seu entendimento sobre inflação, os agentes fundamentais são os setores monopolistas e o Estado. Aqueles são centrais ao crescimento e estabilidade econômica, já que é lá onde se encontram as firmas mais dinâmicas, além dos investidores, empregadores, produtores e exportadores mais importantes. Por isso, segundo essa abordagem, o Estado dá o suporte necessário a tais setores mediante barateamento da infraestrutura, 
incentivos fiscais, financiando direta ou indiretamente parte de seus custos em $\mathrm{P} \& \mathrm{D}$ e apoiando os seus empreendimentos no estrangeiro. Tudo isso constitui gastos para o Estado, que contribuem para a geração de déficits orçamentários persistentes, para o aumento da dívida pública e para a elevação da tendência inflacionária. Segundo a teoria do capital monopolista, essas ações estatais têm impacto direto na inflação, em especial a observável ao fim dos anos 1960. Esse impacto se deu por duas vias: facilitando a elevação da oferta de crédito, o que teria provocado uma superacumulação de capital e níveis recordes de baixa utilização da capacidade instalada, o que conduz a custos excessivamente elevados, provocando um severo achatamento nos lucros, afetando negativamente os setores monopolistas e, consigo, a economia como um todo; e criando o excesso de demanda pelos gastos deficitários e estimulando ininterruptamente o setor monopolista pelas várias políticas monetária e fiscal antidepressivas, conduzindo assim à inflação (Saad-Filho, 2000).

Conforme esta abordagem, afirma Saad-Filho (2000), o setor monopolista e o Estado seriam os agentes responsáveis pelo fenômeno inflacionário. Em qualquer situação de aumento dos custos ou de achatamento dos lucros, o setor monopolista responderia via subida nos preços. No fim dos anos 1960, com a superacumulação de capital e a deterioração dos salários reais, corroídos pela inflação, ficou evidente que o Estado não poderia simultaneamente apoiar os monopólios e financiar o estado de bem-estar social e ao mesmo tempo manter a inflação e o desemprego baixos. A teoria do capital monopolista tem como base o argumento de Hilferding (1985) de que o monopólio impõe preços acima dos preços de produção colimando obter lucro extra. Corroborando o argumento de Kalecki, já que ele entende o poder de monopólio como um fato estilizado, sendo que esta capacidade de obter lucro extra advém de seu poder de mercado. $\mathrm{O}$ preço do monopólio é determinado estrategicamente a fim de maximizar o crescimento da firma, a participação no mercado ou lucros de longo prazo, e são persistentemente inelásticos. O superlucro seria fruto da transferência de valor dos setores competitivos e dos trabalhadores (com salários caindo abaixo do valor da força de trabalho) para os setores monopolistas.

Há uma série de críticas apontadas por Saad-Filho (2000; 2002), indicando limites analíticos ou inconsistências lógicas dessa abordagem. Eentre eles, encontram-se: i) a negligência em explicar o papel da demanda e de outros limitadores ao poder do monopólio, assim como as contratendên- 
cias à concentração e centralização de capital; ii) a pouca clareza em expor os condicionantes que levam o poder de monopólio a afetar o circuito do capital, a circulação monetária e a distribuição de renda, se a inflação pode ou não ser evitada, e em que medida a torna inevitável. Ou mais, porque o poder de monopólio conduz a inflação e não a mudanças pontuais nos preços relativos; iii) apresentação de um entendimento ambíguo sobre o Estado, pois ao mesmo tempo em que ele administra a economia a fim de garantir a reprodução do capital como um todo - o que requer a acomodação de interesses de diferentes frações do capital e dos trabalhadores (melhor alcançado numa democracia) - é visto também como algo próximo de uma ferramenta dos interesses monopolísticos, sendo que sua política se limita pela necessidade de obter consenso - melhor alcançado em regimes autoritários; iv) incapacidade em explicar o conflito capital-trabalho, além da negligência analítica da classe trabalhadora, que é geralmente um espectador do desenrolar dos acontecimentos; v) negligencia o papel do setor financeiro, que não tem as suas ações estudadas em detalhe, além da lacuna analítica referente à restrição do balanço de pagamentos; e vi) compreensão difusa sobre as causas da inflação, já que ela é vista como sendo essencialmente o resultado das políticas econômicas intervencionistas que tentam assegurar o pleno emprego e a estabilidade social, numa economia restringida pelo poder monopolístico e pelas estratégias de preços; as causas da inflação alternam-se entre decisão de preços dos monopólios e o excesso de demanda induzido pelo estado (o que é um resultado paradoxal da tentativa do estado em evitar o subconsumo).

Esta abordagem entende que a concentração e centralização do capital são processos fundamentais dentro do capitalismo e que conduzem necessariamente à monopolização da economia. Ou seja, o desenvolvimento do capitalismo levaria a menos concorrência. Na medida em que os setores monopolistas se estabelecem, teriam a capacidade de determinação arbitrária sobre os preços, controlando a quantidade produzida e impedindo a formação dos preços de produção. ${ }^{8}$ A não necessidade em absorver os capitais que buscam se mobilizar para estes setores mais rentáveis impediriam a entrada de novas firmas, abolindo o processo de concorrência naqueles ramos e permitindo que as respectivas taxas de lucro permanecessem insistentemente acima da média. As consequências desta prática monopo8 Preços de produção das mercadorias são o equivalente aos seus preços de custo acrescidos do lucro médio. Ver Marx (1986, cap. 9). 
lista, ao passo que permite taxas sobrelevadas de lucro, são o aumento moroso de produtividade e produção, gerando problemas para absorver os lucros e, por conseguinte, a estagnação econômica e subutilização dos recursos. Neste caso, o processo competitivo seria o motor da acumulação de capital e não o inverso. Esta abordagem apresenta distinções profundas com a teoria da concorrência de Marx. ${ }^{9}$, que via o desenvolvimento do capitalismo conduzido por leis econômicas que regulavam a sua tendência. Qualquer barreira à livre mobilidade do capital tende a ser derrubada pela cheia da acumulação. A abordagem do capital monopolista entende que o avanço do capitalismo, em vez de potencializar as leis internas que versam sobre a concorrência, assim como as contradições que apontam para os seus limites, de fato, anula tais leis, pari passu suas contradições (Baran; Sweezy, 1974; Marx, 1986).

O lucro diferencial proporcionado pelo poder de monopólio, em Marx, diz respeito a outro fenômeno, que não se deriva do processo de competição. A renda da terra, em termos marxianos, é o excedente oriundo da existência do monopólio da propriedade da terra. Ademais, a produtividade nas atividades agrícolas e de extração tende a ser menor quando comparada com as atividades industriais, em que pese a possibilidade de dissolução desta diferença no longo prazo. Isso acontece pois a existência de poder de monopólio (barreiras à circulação do capital) deriva do fato de que o ingresso de capital não permite ganhos de produtividade na mesma magnitude que ocorre em outros setores industriais. Neste caso, certas condições de produção são impossibilitadas de serem reproduzidas mediante incrementos de investimento. A existência desse direito de monopólio sobre dada condição de produção - impossibilidade de reproduzi-la mediante inversão de capital - implica que a concorrência tem poder reduzido em dirimir o sobrelucro (proporcionado pelo poder de monopólio ao proprietário da condição de produção monopolizada), posto que essa condição de produção não está disponível a qualquer capital, ou seja,

9 A concorrência aparece como se fosse uma necessidade exterior, algo imposto de fora do próprio capital. No entanto, ela deriva-se do processo de acumulação, processo esse que impele a reduzir o valor das mercadorias (oriunda da contradição capital-trabalho) como condição necessária para ganhos de rentabilidade. Isso aparece como um fenômeno vinculado à redução dos custos de produção, mediante aumento da produtividade do trabalho e ingresso de inovação tecnológica. Por isso a busca insaciável de setores e firmas por aumentarem a produtividade e inovarem, que conduz a mobilidade de capital para setores e firmas mais inovadores (inclusive com a formação de grandes corporações) e acirramento da competição intercapitalista, tem a ver com a lei da acumulação de capital. Ver Marx (1986, cap. 9-12). 
não é produtível mediante determinados investimentos de capital. ${ }^{10}$ Poder de monopólio é, assim, a propriedade privada sobre um dada condição de produção que possui a capacidade econômica de "impedir" que o acréscimo de rentabilidade se converta em ganhos de produtividade, nos mesmos termos que acontece em outros setores industriais. Por essa razão, o excesso de valor sobre o preço médio não é nivelado pela concorrência entre capitais. ${ }^{11}$ Ademais, o poder de monopólio gera um impedimento a qualquer capital que queira usar aquela dada condição de produção. Em função disso, o lucro gerado nas atividades com poder de monopólio, como agrícola e extrativista, não participam do processo de equalização. ${ }^{12}$

Transferir as consequências geradas pelo "poder de monopólio" para a teoria da concorrência capitalista, sobretudo mediado pela teoria neoclássica, é um equívoco. ${ }^{13} \mathrm{Na}$ medida em que a terra (ou qualquer outra condição de produção monopolizada) surge como um fator limitado, e com isso os ganhos de produtividade tem um alcance restrito, um aumento na massa de capital-dinheiro disponível não resultaria necessariamente num incremento da quantidade produzida. O processo concorrencial dentro de um setor com poder de monopólio se espalha até o ponto de plena utilização do fator limitante, como é o caso da ocupação de terras cultiváveis. $\mathrm{Na}$ indústria, em geral, ter capital monetário acessível é condição suficiente para implicar um aumento da produção, mesmo que esse aumento varie em tempo de setor para setor. Considerar que um setor industrial que apresente lucros acima da média não fará uso do capital disponível para aumentar sua produção, e assim obter maior ganho, é considerar que cen-

10 "[...] uma força natural monopolizável que, como a queda-d'água, só está à disposição daqueles que dispõem de certos trechos do globo terrestre e seus anexos. [...] Ela só se encontra em certos locais da Natureza e, onde não se encontra, não é produtível mediante determinados investimentos de capital." (Marx, 1983, p. 144).

11 Obviamente supondo mercadorias com valor intrínseco. Marx (1983) explica que mercadorias sem valor, como é o caso de terras não cultiváveis, calcula-se o preço com base na capitalização. No caso dessas terras, seu preço tem por base a quantidade de renda fundiária que o terreno pode gerar num dado período. Ou seja, não é, de fato, o preço de compra do solo, mas da renda fundiária que ele proporciona. Logo, seu preço está vinculado às expectativas de rendimento futuro, uma forma bem parecida do processo de precificação do capital fictício.

12 A existência de distintos setores e firmas possibilita que haja um diferencial na taxa de lucro entre eles. Como o capital migra objetivando auferir o maior rendimento possível, o seu movimento entre os distintos setores tende a igualar o retorno dos capitais segundo a sua magnitude e não segundo a quantidade de trabalho que explora, ou seja, o capital migra de forma a gerar uma tendência de equalização da taxa de lucro. Ver Marx (1986, cap. 9).

13 Para uma crítica precisa a esta assimilação das estruturas de mercado neoclássicas, ver Maldonado-Filho (1990). 
tralização e centralização de capital freiam o ímpeto da acumulação, o que não faz o menor sentido do ponto de vista marxiano. Ademais, a principal conclusão da teoria do capital monopolista no tocante à inflação - que setores monopolistas precificam suas mercadorias, de modo discricionário e persistente, além dos valores médios, em função do poder de monopólio e são ancorados pelo Estado - já era criticada a mais de um século por Marx. Para ele, é um erro entender que poder de monopólio capacite o produtor a estabelecer preços acima do valor da mercadoria. ${ }^{14}$

\section{Teoria da moeda extra}

Esta abordagem foi extensamente estudada por Saad-Filho (2000; 2002) e Saad-Filho e Mollo (2001) e se baseia no texto seminal do De Vroey (1984). A ideia básica da teoria da inflação por moeda extra é que "circunstâncias inerentes aos circuitos de produção e circulação do capital regularmente criam discrepâncias entre a oferta e a demanda de moeda que, em alguns casos, podem gerar inflação" (Saad-Filho; Mollo, 2001, p. 26). O fenômeno inflacionário teria causas fundamentalmente monetárias, em que pese a dimensão da formação dos preços ter certo efeito causal. Quando a emissão de moeda extra e a rigidez de preços geram um efeito superior às mudanças na produtividade (estaria aqui o vínculo com o circuito produtivo), há inflação. ${ }^{15}$ Se o volume de moeda que, na média, é adicionado à circulação cresce, dada a constância na tecnologia e na habilidade da força de trabalho, o aumento nos preços (que, na prática, é acompanhado, normalmente, por mudanças nos preços relativos) é inflacionário. Essa discrepância entre a quantidade de unidades monetárias ofertadas e a massa necessária para fazer o valor do produto por hora de trabalho circular (necessidade das trocas), geradora da moeda extra, pode ser captada apenas ex post.

A moeda extra não é uma particularidade do Estado, assim como a sua existência, per se, não é condição suficiente para desencadear a inflação.

14 "Os que derivam a renda fundiária do monopólio erram ao acreditar que o monopólio capacite o dono de terra a impelir o preço da mercadoria acima do valor. Ao revés, o monopólio consiste em manter o valor da mercadoria acima do preço médio; em vender a mercadoria não acima do valor, mas pelo valor." (Marx, 1983, p. 525, grifos no original).

15 "Concerning the possible causal factors of inflation, our study will focus on two of them, price rigidities and extra-money. A third factor should also be considered, namely changes in productivity." (De Vroey, 1984, p. 382) 
Como o sistema monetário contemporâneo possui duas formas principais de moeda, a emitida pelo Banco Central, que possui o curso forçado e paga qualquer dívida, e a emitida pelos bancos comerciais, que é a forma monetária dos débitos em instituições financeiras privadas, como contrapartida de um direito potencial sobre outras formas de moeda, há, assim, um duplo canal de emissão de moeda extra. Embora o Estado participe da emissão de moeda extra, o principal e mais rotineiro vetor de criação emerge das decisões privadas, que tem substancial autonomia de agir economicamente. Mesmo em relação àquele montante criado pelo Estado, as suas consequências não são de fácil mensuração, no caso, se afeta preços, quantidades ou ambos, já que a discrepância entre a massa monetária ofertada e as necessidades das trocas podem ser eliminadas ou ampliadas por mudanças no produto geral, velocidade de circulação da moeda ou variação no entesouramento (aumento/retração dos fundos capitalistas, por exemplo) (Saad-Filho, 2000; De Vroy, 1984).

Essa abordagem compreende a oferta de moeda como endógena, ou seja, a massa de moeda em circulação é determinada por variáveis do próprio mercado, como volume da produção, preços das mercadorias e pela estrutura institucional do sistema monetário e financeiro (é suposto a velocidade de circulação da moeda como constante). Mudanças em determinadas variáveis, como as supracitadas, alteram diretamente na quantidade de meios entesourados (incluso ativos financeiros) e no volume dos empréstimos bancários, e, por sua vez, na massa monetária. Logo, têm impacto direto na quantidade de moeda em circulação. Essa endogenia não implica a inexistência de desvios entre oferta e demanda de moeda, posto que a velocidade de circulação da moeda não é constante. Ela é determinada fundamentalmente pelas convenções sociais (a regulação das regras financeiras, por exemplo), da estruturada do sistema financeiro e sua relação com a produção, das relações internacionais, das relações de propriedade da economia, do grau de concentração do capital, e de outras variáveis que são mais difíceis de estimar. Ademais, mesmo que o dinheiro de crédito criado corresponda a uma solicitação individual de empréstimo, a oferta total de crédito não reflete as necessidades da economia como um todo. Questões como o auxílio do empréstimo especulativo no aumento da bolha no mercado de ações ou mesmo o financiamento inconsciente de bancos à produção de bens não lucrativos ou invendáveis contribuem para explicar a desproporção. 
Inflação, neste ponto de vista, é produto da discrepância entre valor da moeda criada e o quantum necessário para fazer a produção circular. O ponto de partida é o desentesouramento, via utilização de fundos acumulados, ou a tomada de empréstimos para financiar a produção. A injeção desses fundos na economia aumenta a proporção entre moeda e valor da produção. Esse aumento pode ser esterilizado, caso haja um aumento equivalente na produção ou venda de mercadorias. A venda de mercadorias cria renda adicional, que é usada para pagar as dívidas, financiar a acumulação pela firma, ou ser distribuída entre lucros e dividendos. Esta rota é verossímil apenas se as firmas forem bem-sucedidas nas suas empreitadas. Caso elas sofram perdas e seu produto financiado, quer por dívidas quer por desentesouramento, ou não seja vendido, esse prejuízo pode ser absorvido de duas formas, respeitando ou não um tipo ideal de "regras do jogo". Sobre essas "regras", De Vroey (1984) defini-as partindo de um tipo ideal baseado numa "economia de mercado puro", que implica a minimização das intervenções do Estado. Do ponto de vista do setor privado, as regras funcionam como restrição de pagamento, já que pressupõe que as mercadorias sejam trocadas por dinheiro e que promessas de pagamento sejam honradas. Da perspectiva do Estado, por sua vez, é enfatizado que o financiamento deveria ocorrer apenas por tomada de empréstimo ou por taxação, e a prática de monetização da dívida deve ser encarada como um burlamento das regras da economia de mercado.

Segundo a teoria em questão, o cumprimento das "regras do jogo" (respeito aos prazos e impossibilidade de consolidação de dívida) implica a absorção das perdas pelas próprias firmas, mediante redução do valor de seus ativos, ou pelos bancos, que não terão ressarcidos os empréstimos, caso a empresa entre em falência, e terão que cobrir tal malsucedida empreitada com seus próprios ativos. Obviamente que há outras possibilidades: a transferência das perdas para os trabalhadores das firmas, aumentando temporariamente a taxa de exploração, ou para os consumidores, à custa do aumento dos preços, caso a firma tenha poder de monopólio (nos termos da teoria do capital monopolista). A violação das regras de mercado implica a rolagem da dívida, refinanciada por bancos privados ou pelo Estado. Isso significa injeção de poder de compra na economia, o que pode propagar a distorção entre circulação monetária e produção, criando assim moeda extra. As perdas são compensadas mediante criação de crédito novo, em vez de liquidar a dívida com a renda. Ou seja, bancos privados e 
Estado podem criar moeda extra a fim de cobrir perdas na produção e para postergar ou dirimir problemas econômicos de curto prazo.

Essa abordagem possui diversas lacunas destacadas por Saad-Filho (2000; 2002): o simplismo e a deficiência na análise da oferta do Banco Central e do dinheiro de crédito; a convencional imprecisão que recai ao explicar a relação entre oferta de moeda e a expressão monetária do trabalho. Não é óbvio como a criação de dinheiro (de crédito e fiduciário) se relaciona com a produção e realização do valor e como a expressão monetária do trabalho flutua durante o circuito do capital; a análise sobre o papel da competição intercapitalista é confusa e pouco precisa, já que essa análise sempre trata o capital em geral; iv) não estão bem distintos os aumentos de preço oriundos da moeda extra daqueles causados por outros tipos de crescimento da oferta de moeda. ${ }^{16}$ Ademais, é possível, também, perceber a aderência à teoria cartalista do dinheiro sem valor, defendida por De Vroey (1983), e a abordagem MELT, como se vê em Saad-Filho (2000). A abordagem MELT (monetary expression of labor time) compreende que o valor do dinheiro não lhe é intrínseco e se relaciona à sua capacidade de ser a expressão monetária do tempo de trabalho, como é visto em Foley (1983; 2005) e Moseley (2004; 2005). Doravante, onde estiver escrito $M E L T$, referimo-nos a esta abordagem e não à expressão monetária do trabalho em si.

O valor do dinheiro e o preço das mercadorias são estabelecidos após ser lançado na circulação, conforme a abordagem MELT. Essa compreensão implica que tanto o tempo de trabalho social quanto o valor de troca, expresso em termos monetários, emergem simultaneamente, ou seja, que o valor, social e necessário, e o preço estabelecem-se concomitantemente. Como não há um método que possibilite medir o tempo de trabalho social antes que as mercadorias sejam trocadas por uma dada quantidade monetária, o dinheiro só teria o seu valor estabelecido pari passu à precificação das mercadorias. Ou seja, seriam as decisões de precificação das firmas

16 Um exemplo disto é quando De Vroey (1984) define inflação como algo oriundo da antecipação da obsolescência tecnológica, devido ao poder de monopólio, daquela que se desdobra da moeda extra, dizendo que "lack-of-sale private losses were small because demand was generally high. In these, circumstances obsolescence losses provide the main explanation for the generation of extra-money. [...] obsolescence can explain the rises in specific prices which are at the origin of the process of price-rigidity inflation. As soon as they achieve market power and become price-markets, firms are able to anticipate obsolescence. [...] In other worlds, through this mechanism losses (or more precisely anticipated losses) are made to appear as an increase in costs rather than losses." (De Vroey, 1984, p. 394). 
capitalistas que determinariam os valores e que, seja qual for o momento, qualquer unidade monetária seria capaz de expressar determinada quantidade de trabalho social abstrato. Essa compreensão difere da de Marx, na qual uma questão que se impõe na economia capitalista diz respeito à regulação e distribuição do trabalho social. É a partir do movimento anárquico que os preços se regulam, ou seja, ex post à produção. Somente na venda que o produtor sabe se empregou o tempo de trabalho socialmente necessário, tanto no que diz respeito à tecnologia e ritmo médio de produção, quanto se a quantidade ofertada está de acordo com a demanda. Nos termos de Marx, a venda é o "salto mortal da mercadoria". Por isso que a mercadoria entra no processo de circulação com preço, que valida (ou não) o produto do trabalho privado, e o dinheiro com valor. (Foley, 1983, 2005; Moseley, 2004, 2005).

Na MELT, assim também como em De Vroey (1984), o dinheiro é visto como uma pura forma de aparência do valor, que possibilita a transferência de valores entre as pessoas. Então, o dinheiro seria uma promessa de pagamento socialmente válida, baseado na confiança de que os agentes devem conseguir os valores que de fato eles possuem através da promessa. A forma mais acabada de promessa de pagamento, que sintetize alta capacidade de validação e aligeiramento das trocas seria o crédito, já que a sua forma monetária é per se um título de promessa de pagamento. O caminho percorrido para chegar nessa compreensão é diametralmente oposto ao de Marx. Para ele, o dinheiro é forma independente do valor, o único modo de tornar visível e plasmado a substância/magnitude do valor. Dinheiro de crédito (forma monetária de uma promessa de pagamento) é a forma avançada do dinheiro, mas de modo algum expressa o seu conteúdo. Ao fazer tal incursão teórica, ele dispensa a categoria capital, entendida como secundária para a definição mais precisa e abstrata do dinheiro (este depende apenas da relação social vendedor-comprador). A existência da forma monetária do crédito pressupõe a presença analítica do capital, pois o dinheiro de crédito é emitido quando há a solicitação de empréstimo contra um capital latente que está acomodado no sistema bancário. Assim, o dinheiro de crédito possui a característica do dinheiro, ao funcionar sobretudo liquidando dívidas, e do capital, na medida em que compra força de trabalho e meios de produção. Funcionar como meio de pagamento é uma mera derivação lógica da natureza do dinheiro e qualquer forma monetária que cumpra esta função atua como seu representante. 


\section{Críticas metodológicas}

As teorias marxistas da inflação aproximam-se ou se afastam umas das outras a depender do corte teórico secundário empregado. Há a utilização de abordagens teóricas não-marxistas, como é o caso da linha cartalista, no entendimento sobre dinheiro, pós keynesiana, ao tratar sobre crédito e sua extensão monetária, Kaleckiana, na perspectiva da determinação de preços e salários, além de teorias mais convencionais, como é o caso do Rowthorn (1984) com as expectativas adaptativas do monetarismo, Baran e Sweezy (1974) com as estruturas neoclássicas de mercado, e De Vroey (1984) com as "regras do jogo" da Nova Economia Institucionalista. No afã de dar uma resposta teórica convincente para um fenômeno relativamente novo ${ }^{17}$ e na crença de que a teoria econômica do Marx seria insuficiente no fornecimento de um arcabouço com alta capacidade explicativa, as teorias da inflação aderiram não apenas conceitualmente, mas também à forma de fazer abstrações de tradições não-marxistas. $O$ diferencial no método do Marx é ver os fenômenos como síntese de múltiplas relações, porém reconhecendo a existência de alguns fatores, dentro desta vigorosa interação, com maior poder de influência e encadeamento, logo, com maior capacidade explicativa (determinação dialética). Destarte, para identificá-los, ou seja, para localizar os fatores determinantes, deve-se fazer uso da abstração, isolando analiticamente o fenômeno estudado de elementos que lhes são estranhos. E isto, para não incorrer no equívoco do indutivismo simplista, que é a formulação de uma teoria baseada na aparência dos fenômenos, sem descer a níveis explicativos mais profundos; muito menos na monocausalidade mecânica, que escamoteia as interações e os processos. Abstrações imprecisas produzem má compreensão dos fenômenos.

Para não incidir no erro de fazer abstrações imprecisas, deve-se retirar da análise todas as relações e processos secundários. Se a inflação crônica é entendida como desvalorização da moeda legal, que se expressa num aumento persistente e ininterrupto do nível geral de preços, o ponto de partida deve ser a categoria preço. O seu entendimento mais basilar, que diz respeito a determinações na sua essência, prescinde outros fatores mais concretos. No nível analítico da circulação mercantil simples, o preço é

17 A inflação crônica surge como fenômeno relevante ao fim da década de 1960. A partir de então, a teoria econômica tenta dar respostas aceitáveis para tal fenômeno, colocando-o como o centro da análise e não mais como uma questão secundária. 
basicamente o valor da mercadoria apresentado em termos monetários. O seu estabelecimento depende da existência de formas monetárias que sirvam como unidade de conta (libra, dólar, marco, entre outras) e de uma relação estável entre o meio circulante (moeda) e o dinheiro (mercadoria com funções monetárias que expressam o valor das outras mercadorias), que é chamado padrão dos preços (ex. 1 libra = X kg de ouro). A variação dos preços derivar-se-ia de mudanças nos valores das mercadorias vulgares ou da mercadoria-dinheiro, alterando a expressão dos valores em termos de dinheiro, ou da mudança do padrão dos preços, alterando a quantidade de meios circulantes que representaria um dado quantum de dinheiro. Dispensa-se, neste grau de explicação, conceitos como competição intercapitalista, poder de monopólio, crédito bancário, etc., porque estes resultariam da categoria capital, que se dá num nível de análise distinto da circulação simples. Ao incorporar relações como reivindicações sobre a renda e competição entre unidades produtivas, as abordagens do conflito distributivo e do capital monopolista afastam-se da compreensão mais basilar da inflação, no caso, ser fundamentalmente monetária.

Da mesma forma que a concorrência não está no mesmo nível de abstração da fixação dos preços (o valor expresso em termos monetários padronizáveis), ocorre também a distinção entre o dinheiro de crédito e o dinheiro. O nível analítico de onde se deriva a categoria dinheiro é na circulação mercantil simples, cujos pressupostos, como apresenta Germer (1995), são: os produtores são independentes e donos dos meios de produção; ${ }^{18}$ há o reconhecimento social da propriedade privada dos meios de produção e do produto; as transações são realizadas por meio de trocas voluntárias nos mercados; os contratos são os instrumentos jurídicos que regulam as trocas entre os agentes econômicos e; consequentemente, o produto do trabalho humano aparece como mercadoria (que sejam úteis e tenham valor). A circulação capitalista, em que a categoria dinheiro de crédito encontra-se plenamente desenvolvida, possui todas as relações pressupostas na circulação simples, porém com uma distinção: há uma divisão de classe entre os proprietários dos meios de produção e os proprietários da força de trabalho. Neste caso, é uma expansão da relação social comprador-vendedor da circulação simples, tendo em vista que, assim, haverá um grupo de compradores e vendedores de uma mercadoria 18 "a produção é realizada por produtores individuais independentes, proprietários dos seus meios de produção." (Germer, 1995, p. 7). 
especial, a força de trabalho. Esse elemento é vital e submete todos os outros à sua lógica, visto que possibilita a emergência do capital: um valor dinâmico, que muda de forma, e na produção se autoexpande. Como o dinheiro de crédito, na sua forma plenamente desenvolvida ${ }^{19}$, é uma categoria oriunda da interação entre elementos constitutivos do dinheiro e do capital, deve estar pressuposto o crédito bancário (empréstimo monetário objetivando juros) e o capital de empréstimo (forma latente do capital monetário, disponível aos capitalistas funcionantes por meio de empréstimo). A circulação simples é dominada pela relação-valor, cuja aparência só se efetiva mediante dinheiro. Na circulação capitalista, por sua vez, a relação-capital agrega-se à relação-valor da circulação mercantil simples, e implica uma composição crescente do dinheiro de crédito como meio de troca, que expulsa o dinheiro da circulação, conduzindo-o a funcionar normalmente como medida dos valores, logo, na determinação dos preços, em última instância.

Por mais que o dinheiro de crédito desempenhe funções monetárias, ele não é e nem pode ser dinheiro, já que é a forma monetária das dívidas de instituições financeiras privadas. $O$ dinheiro, por sua vez, é a forma da aparência do valor, o único meio pelo qual a quantidade dos valores pode ser representada. Para tanto, esta "coisa" objetivada deve possuir valor intrínseco, ser um produto inequívoco do trabalho humano, no caso, ser mercadoria. Segundo Germer (2005), o ouro é por excelência a mercadoria que sintetiza o particular e o social, necessário para constituir o dinheiro. Esta compreensão se deriva do impasse: por um lado, o reconhecimento social não é suficiente para que o produto de um trabalho particular seja diretamente trocado pelo produto de outro trabalho particular, e por outro, cada produto de um trabalho particular pode apenas ser trocado pelo produto de outro trabalho da mesma forma particular. Esse impasse só pode ser resolvido se existir o produto de um trabalho particular que entra na circulação como produto de um trabalho que é diretamente social, então, aqueles produtos dos trabalhos particulares podem ser trocados por este. Esta é uma solução gerada espontaneamente na forma do produto de um

19 O dinheiro de crédito, enquanto um instrumento de dívida que cumpre funções monetárias, tem o seu estágio lógico derradeiro após a emergência do crédito bancário. Em que pese a existência desta conclusão, sua origem está ligada à circulação mercantil simples, quando títulos de crédito comercial funcionavam como meio de troca, assim como afirma Marx (1996). No entanto, a sua ampla aceitação e disseminação se deu quando bancos passaram a emiti-los, mediante crédito bancário. 
trabalho particular, no caso, uma mercadoria, que é socialmente construída como a representação direta do trabalho social. "This product of a labour that is simultaneously particular and social is the money commodity, whose finished form in capitalism is gold". (Germer, 2005, p. 30-1).

Ser essa mercadoria diretamente social faz parte da natureza do dinheiro. Não há economia mercantil, cuja pressuposição é a existência de intercâmbios de produtos indiretamente sociais, se não houver uma mercadoria socialmente validada. Assim, é condição necessária para que as trocas multilaterais se realizem, isto é, para que haja a validação de produtos do trabalho privado, uma mercadoria especial que já adentre no intercâmbio validada. Essa mercadoria é o ouro. Qualquer forma monetária deve estar economicamente vinculada a ele para poder exercer as funções do dinheiro, mesmo que não exista qualquer vínculo jurídico. $O$ fim da conversibilidade das moedas legais com o ouro, no pós Bretton Woods, de modo algum torna esta teoria do dinheiro inadequada ao entendimento da realidade, em que pese Foley (1983; 2005), Paulani (2011; 2014), Rotta e Paulani (2009), Moseley (2005), Reuten (1988), entre outros, afirmarem o contrário. Isso sobretudo porque, como indica Marx (2011, p. 83), "a conversibilidade não se revela na caixa do banco, mas na troca cotidiana", nas relações mais convencionais de intercâmbio. A vinculação econômi$\mathrm{ca}^{20}$ "permanece, por conseguinte, requisito de todo dinheiro cujo título o faz um signo de valor, isto é, o iguala, como quantidade, a uma terceira mercadoria." (Marx, 2011, p. 85).

A respeito dos questionamentos feitos sobre o vínculo econômico, Astarita indica que,

La respuesta se puede dar según el mismo criterio con que Marx consideraba el billete inconvertible de Prusia [ $\left.{ }^{21}\right]$ como un signo de oro: de hecho, en el mercado

20 "Não há qualquer dúvida [...] que, enquanto o dinheiro de papel retém sua denominação em ouro (p. ex., que uma nota de 5 libras é a representante em papel de 5 soberanos [moeda de ouro inglesa, que valia 1 libra esterlina]), a conversibilidade da nota em ouro continua sendo para ela uma lei econômica, quer esta exista politicamente ou não. De 1799 a 1819, as notas do Banco da Inglaterra também continuavam a declarar que representavam o valor de um determinado quantum de ouro. Como pôr à prova essa afirmação senão pelo fato de que a nota realmente comanda tal e qual quantidade de metal? A partir do momento em que para uma nota de $£ 5$ não se pode mais obter valor em metal $=5$ soberanos, a nota era depreciada, muito embora fosse inconversível. A igualdade do valor da nota com um valor de ouro determinado, expresso em seu título, entrou imediatamente em contradição com a desigualdade factual entre nota e ouro" (Marx, 2011, p. 82, itálico original).

21 "Um táler de papel declara representar o mesmo valor que um táler de prata. Caso a confiança no governo fosse profundamente abalada, ou caso esse dinheiro de papel fosse emitido 
del oro se establece la vinculación del billete con el metal. Y es en las corridas cuando esta vinculación adquiere una importancia insoslayable. Por eso hoy cuando se habla de la "cotización del oro" no se la debe considerar con el mismo status que tiene la cotización de cualquier otro metal en los mercados internacionales, sino como la expresión mistificada del contenido oro del billete. $O$ sea, $[\ldots]$ el precio del oro es una expresión del valor del dólar. Así, si desde principios de octubre de 2002 a marzo de 2005 el oro subió su precio de 320 a 425 dólares, según este criterio el dólar pasó de valer 0,003125 onzas de oro a valer 0,0023529 onzas. [...] Las instancias legales y políticas sobredeterminan este desarrollo [da relação de separação do signo com o ouro]. De ahí la autonomización del signo con respecto al oro, y las largas divergencias que pueden producirse entre el precio del oro en los mercados (= valor del billete) y sus costos de producción. Esta posibilidad de divergencia todavía se potencia porque el oro, en cuanto reserva de valor, permanece atesorado en su mayor parte. Esto explica, además, las fluctuaciones de su precio, ligadas a desatesoramientos o atesoramientos, cualitativamente distintas de lo que sucede con cualquier otra mercancia. (Astarita, 2006, p. 16-7).

O dinheiro de crédito, por sua vez, desenvolve-se a partir da articulação entre o crédito comercial e monetário e significa uma inovação do capitalismo no sentido de desenvolver sua esfera de trocas, rompendo os limites impostos pela base metálica (tanto no que diz respeito aos custos econômicos de sua disponibilidade quantitativa, quanto sua velocidade de circulação). No ambiente em que vigora o sistema de crédito moderno, o crédito pode ser utilizado para liquidar dívidas, esta que outrora se reservava exclusivamente à moeda metálica. Desse modo, enquanto o crédito encontra-se submetido às leis de circulação monetária, ganha contornos de dinheiro, possibilitando-o ser chamado de dinheiro de crédito. Este deve ser entendido enquanto uma categoria complexa, enquanto uma síntese de elementos derivados do dinheiro e do capital. Por isto se deve ter em mente que a forma acabada do dinheiro de crédito supõe a existência do crédito bancário e este, por sua vez, a forma capital de empréstimo, enquanto um produto da categoria capital. De fato, dinheiro de crédito nem é dinheiro e nem capital. Nas palavras de Germer (2001),

a sua derivação do dinheiro reconhece-se pelo fato de o dinheiro de crédito ter origem na função de meio de pagamento e de ser essencialmente uma categoria da esfera da circulação, na qual substitui - ou representa - o dinheiro (=ouro), realizando as suas funções de meio de circulação e de pagamento. A sua derivação do capital, por outro lado, está clara no fato de ser ele produzido pelo sistema de crédito gerado pelo desenvolvimento do capitalismo, a partir das relações de crédito comercial e bancário entre capitalistas. Como objeto de análise, o dinheiro de crédito constitui rigorosamente um capitulo do estudo da esfera da circulação, pois o dinheiro de crédito não é dinheiro, é apenas meio circulante. [...] O dinhei-

em proporção maior do que a exigida pelas necessidades do curso (Umlauf), o táler de papel deixaria de equivaler na prática ao táler de prata e seria depreciado, porque teria caído abaixo do valor que seu título anuncia." (Marx, 2011, p. 83). 
ro de crédito designa, portanto, títulos de crédito que desempenham as funções do dinheiro (=ouro) na circulação, derivados da letra de câmbio como forma original. [...] Mais tarde, o depósito tornou-se gradualmente a forma principal de dinheiro de crédito, que ainda é atualmente, ao passo que as cédulas do Banco Central foram reduzidas a instrumentos que realizam as funções da circulação nas transações de menores valores. (Germer, 2001, p. 209-10).

Assim, ao incorporar crédito bancário na abstração mais geral do dinheiro, a abordagem da moeda extra afastou-se do entendimento do dinheiro como forma independente do valor (autonomizada em relação ao produto) e equivalente geral, e da moeda como representante que exerce funções do dinheiro. Ao se deixar levar pelas aparências, cuja atuação monetária é hegemonizada pelo dinheiro de crédito, misturou níveis diferentes de abstração, fazendo transparecer que a teoria do dinheiro marxiana é obsoleta. O processo analítico e teórico elaborado por Marx foi mais criterioso, partindo inicialmente de um nível mais profundo da abstração para formular a sua teoria do dinheiro, para então incorporar elementos concretos, secundários àquele grau de análise, e formular a categoria dinheiro de crédito, concebida apenas num nível mais concreto da produção de valor. $\bigcirc$ fato de o dinheiro de crédito desempenhar diversas funções monetárias não muda a essência do dinheiro ou suas determinações intrínsecas, mas altera a sua forma. Um estudo baseado em Marx deve preocupar-se em explicar quais as determinações que causam tal mudança de forma e não aderir às pressões empiricistas que pressupõem uma alteração da natureza do dinheiro.

Não se deve confundir as determinações formais do dinheiro com as determinações intrínsecas, que dizem respeito à sua natureza. São as necessidades das trocas, derivadas da acumulação de capital, que determinam como o dinheiro aparecerá, sob qual manto ele será representado. Ele pode aparecer formalmente como outra coisa, que tenha a sua relação diretamente perceptível (como é o caso dos signos de valor) ou mais indireta e cheia de mediações (como é o caso do dinheiro de crédito). A própria rotina da acumulação complexifica essas determinações formais, gerando a falsa ideia de que uma mudança na forma implica uma mudança na natureza do fenômeno. A forma é o aspecto de uma relação, centrado tanto na aparência quanto na função, cujas determinações intrínsecas são definidas. É por essa "forma" que é possível encontrar identidade na diferença. Dinheiro e dinheiro de crédito são obviamente diferentes em diversos aspectos, porém idênticos como forma monetária, assim como capital e o dinheiro de crédito como distintos e similares. Esta noção dá a possibilidade 
de ver as coisas idênticas e distintas concomitantemente, e isto porque são expressões diferentes do mesmo fato. Vendo essa dependência mútua dentro de cada parte que interage e cada parte como um aspecto necessário das outras, elas se tornam idênticas em expressar o mesmo todo, porém deixando patente suas diferenças formais. A identidade e diferença dependerá do nível de análise e da extensão da abstração feita (Ollman, 2003).

Assim, como a inflação crônica surgiu num momento de intensificação das lutas entre trabalhadores e capitalistas, a teoria do conflito distributivo concluiu que as reivindicações sobre a renda disponível eram o seu fator causal. Em vez de ver essas lutas como uma tentativa de defesa das classes contra a deterioração persistente de seu poder aquisitivo nominal por causa da desvalorização irrevogável da moeda legal, ou seja, o que é apontado como causa seria consequência. Como os capitalistas têm maior poder ${ }^{22}$ e instrumentos de defesa a essa deterioração, pois com o advento das grandes corporações ficou mais fácil acessar ativos financeiros com correção monetária, a teoria do capital monopolista viu esse poder como a causa da inflação crônica e não como a seu efeito. A realidade aparece invertida: o que é produto parece ser o fator causal. Sobre a base da determinação dialética, a desvalorização da moeda (depreciação do padrão dos preços) pode causar reivindicações sobre a renda como defesa à perda do poder aquisitivo ou até mesmo à criação de instrumentos que ampliem esse poder defensivo, mas não o inverso. Entretanto, apenas reconhecer os fatos não é o suficiente, pois é muito fácil focar nas aparências. É provável que, ao se deparar com a evidência empírica da inconversibilidade jurídica das moedas de curso legal ao ouro, conclua-se que o dinheiro perdeu a sua natureza mercantil. Desse modo, as mercadorias seriam precificadas eo dinheiro teria o seu valor formado na circulação e não na produção, como concebe a abordagem da moeda extra. Para superar este problema de abstrações imprecisas, é preciso recorrer às precisões da teoria monetária do Marx e do seu método.

22 Mesmo a escola Pós-Keynesiana reconhece esse fato. Cardim de Carvalho (1989, p. 183) expõe, no "axioma da decisão", que firmas visam maximizar acumulação de dinheiro e trabalhadores obtenção de bens de consumo. O produto disto é que o poder de decisão sobre os processos econômicos é distribuído de forma desigual: "as decisões empresariais são as que regem a operação de uma economia monetária porque elas detêm os meios com os quais a atividade produtiva pode ser exercida. [...] As firmas têm o poder de decisão de iniciar ou não processos de produção por que nestas economias o capital é 'escasso', inacessível assim aos trabalhadores. A escassez permite aos empresários [...] decidir, entre alternativas existentes, quando e onde se utilizar o capital.". 
Esse problema metodológico, oriundo do foco exclusivo na aparência, além de gerar uma compreensão atrofiada sobre as relações internas, como já exposto, secundariza a importância do processo histórico de estabelecimento da inflação crônica. A mudança na forma desempenhadora da função do dinheiro mundial, no caso, a substituição do dinheiro (ouro) pelo dinheiro de crédito (sob a forma contratual da unidade de conta dos países centrais), derivado da pulverização das trocas mediadas por promessas de pagamento (no fim do pós $2^{a}$ Guerra), coincidiu com a emergência da inflação crônica, e não a esmo. A estabilidade das moedas nacionais estava diretamente vinculada à sua capacidade de ser uma expressão confiável do dinheiro (ouro). Como esta ligação jurídica foi paulatinamente sendo desfeita, o vínculo econômico tornou-se mais complexo e embebecido de desconfiança, desdobrando-se num processo de desvalorização endêmica das moedas locais ${ }^{23}$ ou de depreciação do padrão dos preços. ${ }^{24} \mathrm{O}$ que significa compreender a inflação crônica como derivado de um processo histórico e ver os fatores que lhe constituem como internos. A inflação crônica é entendida como uma relação complexa (envolve tanto elementos orgânicos quanto históricos) que surgiu como resultado de condições específicas. Ver seus fatores constitutivos, sobretudo a mudança na forma do dinheiro mundial, como externos implica tratá-la como um fenômeno a-histórico. Para superar a incompreensão do processo, deve-se tanto reconhecer a importância da forma do dinheiro mundial na estabilidade do valor das

23 "Na Alemanha Ocidental, a circulação de papel-moeda subiu de 14 bilhões de marcos em 1955 para 47,5 bilhões em 1973, mas os empréstimos bancários a firmas domésticas e a particulares subiu, no mesmo período de 63 para 631 bilhões de marcos. No Japão, a circulação de papel-moeda passou de 422 bilhões de yens em 1950 para 5.556 trilhões em 1970, mas os empréstimos bancários aumentaram de 2.500 yens em 1952 para 39.500 bilhões de yens em 1970. O caso da Bélgica [...] também merece ser citado. No período 1962/71, os créditos bancários ao setor público subiram para 210 bilhões de francos belgas, isto é, quase duplicaram enquanto os créditos bancários à economia privada passaram de 72 para 340 bilhões de francos belgas, ou seja, aumentaram quase 5 vezes. Mas durante o mesmo período, o Produto Nacional Bruto, a preços constantes, subiu aproximadamente 55\%." (Mandel, 1985, p. 294). $24 \mathrm{Na}$ medida em que o dinheiro de crédito é utilizado como forma usual de meio de compra e de pagamento, a consequência na massa monetária é direta. Shaikh argumenta que qualquer unidade que gasta acima de sua renda atual (gasto deficitário) só pode se financiar mediante uma baixa em seus ativos (reduzindo seus fundos) ou tomando crédito. O significado econômico dessa ação é a criação de novos créditos por parte dos bancos privados e expansão da base monetária (dinheiro fiduciário), por parte do Banco Central. Nesse caso, o novo crédito e a expansão da base monetária não tem relação direta com a satisfação da demanda por dinheiro como ativo líquido (a geração endógena de excesso de oferta monetária que se desdobra em excesso de demanda agregada). Esses gastos deficitários, "combinado con las entradas de poder adquisitivo procedente del exterior, pueden producir, por tanto, una presión persistente sobre los diferentes mercados, en especial sobre el mercado de bienes." (Shaikh, 2000a, p. 38). 
moedas nacionais quanto entender as mudanças nesta forma ao longo da história como determinadas pelo desenvolvimento do capitalismo, ou seja, são produtos do aguçamento das leis econômicas preconizadas por Marx e não a sua negação.

\section{Conclusões}

Este texto apresentou, ainda que de modo breve, os principais argumentos que subjazem as teorias marxistas da inflação. Enquanto que as abordagens do conflito distributivo e do capital monopolista veem o processo inflacionário como produto da ação intensa e desequilibrante das classes sociais, tendo o Estado como um sancionador; a teoria da moeda extra o entende como fundamentalmente monetário, fruto do descompasso entre oferta e demanda por dinheiro de crédito. A função da moeda na inflação é secundarizada pela teoria do conflito distributivo e pela teoria do capital monopolista, vista exclusivamente como uma força potencializadora do poder de mercado exercido pelas classes sociais. Por sua vez, a teoria da moeda extra está sustentada numa noção cartalista de dinheiro, cujas mercadorias se precificam apenas na circulação e o dinheiro tem seu valor baseado na sua capacidade de expressar o trabalho social. Há em comum nessas abordagens um afastamento da teoria do dinheiro de Marx, sustentada pela hipótese do equivalente geral e de que o dinheiro entra na circulação com valor. Desse modo, é patente a dificuldade que elas têm em vincular suas abordagens com a teoria do valor marxiana e suas derivações mais basilares.

O uso pouco preciso da abstração pode ser a origem do afastamento dessas teorias em relação à abordagem de Marx. A sua observação sobre os fenômenos e a sucessiva formulação de leis econômicas baseadas nos fatores reguladores é produto de uma abstração que transcende a superfície dos tais fenômenos. Isto significa a inclusão de fatores mais concretos no nível analítico devido, para evitar a formulação de teorias que forneçam uma visão distorcida e incapaz de indicar os fatores realmente determinantes. No nível da aparência, por exemplo, o lucro apresenta-se como uma remuneração do fator fornecido pelo capitalista, da mesma forma que o salário parece ser o pagamento de um trabalho realizado. Na superfície, as trocas são realizadas entre indivíduos iguais e livres, porque supostamente todos são proprietários, uns da mercadoria "capital" e outros da mercadoria trabalho. 
Os proprietários do trabalho alugam a sua mercadoria ao proprietário do "capital", que a utiliza como insumo à sua produção. Neste nível analítico, parece que a remuneração dos fatores trabalho e capital são equivalentes às suas contribuições ao produto. Porém, se a abstração sair do nível da aparência e for para um nível mais profundo, perceberá que o indivíduo não é proprietário da mercadoria trabalho, mas sim de sua capacidade de trabalhar, de sua força de trabalho. Neste nível de análise, o salário é visto como ele é, enquanto a remuneração necessária para reproduzir a força de trabalho, e o capital não mais como um fator da produção ou uma de suas múltiplas formas, mas como uma relação social, resultado de um fluxo contínuo de produção de mais-valor (riqueza criada pelos trabalhadores que não the é devolvida). Este excedente aparece sob formas distintas (lucro, juros, impostos, etc.), mas tendo em comum este aspecto que toca em suas origens. A realidade aparece invertida, fazendo parecer que as relações de trabalho implicam a troca de equivalentes e não numa relação de exploração (apropriação do valor gerado por um trabalho não pago), e que o capital é meramente uma de suas formas e não uma relação social. Por isto, a conclusão central deste artigo é que a aderência, por parte das teorias marxistas da inflação, a este método focalizado na superfície, produziu uma dificuldade em localizar a essência do fenômeno inflacionário e implicou um inequívoco afastamento em relação à teoria econômica de Marx.

Apesar disso, a ideia trazida pela teoria da moeda extra, de que a inflação se deriva de uma depreciação persistente do padrão dos preços, pode fornecer bons fundamentos para melhor compreender tal fenômeno. A emissão monetária num volume maior do que a necessidade das trocas (aqui entendida como a massa de dinheiro que circularia caso o meio de compra estivesse em corpo áureo) afeta a capacidade da unidade de conta de ser um representante crível do valor, implicando a sua desvalorização. A alteração no padrão dos preços é produto da lei do valor, a qual regula a troca de quantidades de valores das mercadorias por valores equivalentes da mercadoria-dinheiro. Quando as proporções da unidade de conta estão em quantidades superiores a que dizem economicamente representar em termos de dinheiro (ouro), há um reajustamento da relação massa da moeda legal - quantum de dinheiro representado. $O$ resultado disso é uma alteração dos preços em termos da moeda legal das mercadorias. A abordagem da moeda extra pode contribuir para o entendimento dos fatores que levam à emissão excessiva. 


\section{Referências}

ASTARITA, Rolando. Concepciones sobre el Dinero, el Rol del Oro y Cuestiones Monetarias. Realidad económica, Buenos Aires, p. 17, 11 mar. 2006. Disponível em: <http://www.iade. org.ar/modules/noticias/makepdf.php? storyid=1500 >. Acesso em: 8 fevereiro 2016.

BARAN, Paul A.; SWEEZY, Paul M. Capitalismo monopolista: ensaio sobre a ordem econômica e social americana. Rio de Janeiro: Zahar editores, 1974.

BERNSTEIN, Peter L. Against the gods: The remarkable story of risk. New York: John Wiley \& Sons, 1996.

BRYAN, Michael F. On the Origin and Evolution of the Word Inflation. RABIN, Jack; STEVENS, Glenn (eds.). Handbook of monetary policy. New York: Marcel Dekker, 2002. p. 593-599.

CARVALHO, Fernando Cardim de. Fundamentos da Escola Pós-keynesiana: A Teoria de uma Economia Monetária. In: AMADEO, Edward. Ensaios sobre Economia Política Moderna: Teoria e História. São Paulo, Marco Zero, 1989.

DE VROEY, Michel. Inflation: a non-monetarist monetary interpretation. Cambridge Journal of Economics, v. 8, p.381-399, 1984.

DRAPER, Hal. Karl Marx's theory of revolution. Vol. 1: State and bureaucracy. New York: Monthly Review Press, 1977.

FOLEY, Duncan. On Marx's Theory of Money. Social concept, New York, v.1, n.1, p. 5-19, 1983.

FOLEY, Duncan. Marx's Theory of Money in Historical Perspective. In: MOSELEY, Fred (Ed.). Marx's theory of money: Modern Appraisals. London: Palgrave, 2005.

GERMER, Claus. Dinheiro, capital e dinheiro de crédito: o dinheiro segundo Marx. Tese (Doutorado em Economia) - Universidade Estadual de Campinas, Campinas, 1995.

GERMER, Claus. Dinheiro e dinheiro de crédito no capitalismo avançado. Ensaios FEE, Porto Alegre, v. 22, n. 1, p. 205-228, 2001.

GERMER, Claus. The Commodity Nature of Money in Marx's Theory. In: MOSELEY, Fred (Ed.). Marx's Theory of Money: Modern Appraisals. London: Palgrave, 2005.

HILFERDING, Rudolf. O capital financeiro. São Paulo: Nova Cultural, 1985.

MALDONADO FILHO, Eduardo. A dinâmica da concorrência em Marx. In: Anais do $18^{\circ}$ Encontro Nacional de Economia, dezembro, vol. 1, p. 107-126, 1990.

MALDONADO FILHO, Eduardo. Marx e o Capitalismo Contemporâneo. In: PAULA, J. A. (org.) Adeus ao desenvolvimento - a opção do governo Lula. Belo Horizonte: Autêntica, 2005.

MANDEL, Ernest. O Capitalismo tardio. São Paulo: Nova Cultural, 1985.

MARX, Karl. Teorias da mais-valia - Volume II. São Paulo: Difel, 1983.

MARX, Karl. O capital - Crítica da Economia Política. Volume VI. Livro Terceiro. São Paulo: Nova Cultural, 1986.

MARX, Karl. O capital - Crítica da Economia Política. Volume I. Livro Primeiro. São Paulo: Nova Cultural, 1996.

MARX, Karl. Grundrisse. São Paulo: Boitempo editorial, 2011.

MOSELEY, Fred. Introduction. In: MOSELEY, Fred (Ed.). Marx's theory of money: Modern 
Appraisals. London: Palgrave, 2005.

MOSELEY, Fred. The "monetary expression" of labor in the case of non-commodity money. Texto para discussão. Mount Holyoke College, p. 13, nov. 2004. Disponível em: <http:// www.mtholyoke.edu/ fmoseley/Working_Papers_PDF/melt.pdf $>$. Acesso em: 02 de abril 2014.

OLLMAN, Bertell. Dance of the dialectic: Steps in Marx's method. Urbana/Chicago: University of Illinois Press, 2003.

PAULANI, Leda M. A autonomização das formas verdadeiramente sociais na teoria de Marx: comentários sobre o dinheiro no capitalismo contemporâneo. Revista EconomiA, Brasília, v. 12, n.1, p. 49-70, jan-abr, 2011.

PAULANI, Leda M. Money in contemporary capitalism and the autonomisation of capitalist forms in Marx's theory. Cambridge Journal of Economics. v. 38, n. 4, p. 779-795, 2014.

REUTEN, Geert. The money expression of value and the credit system: a value-form theoretic outline. Capital and class, London, n. 35, p. 121-142, 1988.

ROTTA, T. N.; PAULANI, L. M. A teoria monetária de Marx: atualidade e limites frente ao capitalismo contemporâneo. Economia, v. 10, n. 3, p. 609-633, set./dez. 2009.

ROWTHORN, Bob. Capitalismo, conflito e inflação: ensaios de economia política. Rio de Janeiro: Zahar Editores, 1982.

SAAD-FILHO, A.; MOLLO, M. L. Reconhecimento social da moeda: observações sobre a inflação e a estabilidade de preços no Brasil. Revista de Economia Política, v. 21, n. 2 (82), p. 24-42, abr-jun 2001.

SAAD-FILHO, Alfredo. Inflation theory: a critical literature review and a new research agenda. Research in Political Economy, v. 8, p. 335-362, 2000.

SAAD-FILHO, Alfredo. The value of Marx: political economy for contemporary capitalism. London: Routledge, 2002.

SHAIKH, Anwar. Inflación y desempleo: una alternativa a la teoría económica neoliberal. In: GERRERO, Diego. Macroeconomía y crisis mundial. Madrid: Ed. Trotta, 2000a.

SHAIKH, Anwar. Los tipos de cambio reales y los movimientos internacionales de capital. In: GUERRERO, Diego (Ed.). Macroeconomia y crisis. Madrid: Trotta, 2000 b.

\section{Sobre os autores}

Giliad de Souza Silva - giliad.souza@unifesspa.edu.br

Universidade Federal do Sul e Sudeste do Pará, Marabá, Pará.

Eduardo Augusto de Lima Maldonado Filho - eduardo.maldonado@ufros.br

Universidade Federal do Rio Grande do Sul, Porto Alegre, Rio Grande do Sul.

\section{Sobre 0 artigo}

Recebido em 16 de outubro de 2015. Aprovado em 31 de março de 2016. 